\title{
Overwintering of Sclerotium rolfsii and S. rolfsii var. delphinii in Different Latitudes of the United States
}

Z. Xu, M. L. Gleason, D. S. Mueller, and P. D. Esker, Department of Plant Pathology, Iowa State University, Ames 50011; C. A. Bradley, Department of Plant Pathology, North Dakota State University, Fargo 58105; J. W. Buck, Department of Plant Pathology, University of Georgia, Griffin 30223; D. M. Benson, Department of Plant Pathology, North Carolina State University, Raleigh 27695; P. M. Dixon, Department of Statistics, Iowa State University, Ames 50011; and J. E. B. A. Monteiro, Department of Exact Sciences, ESALQ, University of Sao Paulo, Piracicaba, Brazil

\begin{abstract}
Xu, Z., Gleason, M. L., Mueller, D. S., Esker, P. D., Bradley, C. A., Buck, J. W., Benson, D. M., Dixon, P. M., and Monteiro, J. E. B. A. 2008. Overwintering of Sclerotium rolfsii and S. rolfsii var. delphinii in different latitudes of the United States. Plant Dis. 92:719-724.

Previously known only from the southern United States, hosta petiole rot recently appeared in the northern United States. Sclerotium rolfsii var. delphinii is believed to be the predominant petiole rot pathogen in the northern United States, whereas $S$. rolfsii is most prevalent in the southern United States. In order to test the hypothesis that different tolerance to climate extremes affects the geographic distribution of these fungi, the survival of $S$. rolfsii and $S$. rolfsii var. delphinii in the northern and southeastern United States was investigated. At each of four locations, nylon screen bags containing sclerotia were placed on the surface of bare soil and at 20-cm depth. Sclerotia were recovered six times from November 2005 to July 2006 in North Dakota and Iowa, and from December 2005 to August 2006 in North Carolina and Georgia. Survival was estimated by quantifying percentage of sclerotium survival on carrot agar. Sclerotia of $S$. rolfsii var. delphinii survived until at least late July in all four states. In contrast, no S. rolfsii sclerotia survived until June in North Dakota or Iowa, whereas $18.5 \%$ survived until August in North Carolina and $10.3 \%$ survived in Georgia. The results suggest that inability to tolerate low temperature extremes limits the northern range of $S$. rolfsii.
\end{abstract}

Additional keywords: Hosta spp., ornamental crops

Petiole rot, caused by Sclerotium rolfsii and $S$. rolfsii var. delphinii, has caused significant economic losses to hosta (Hosta spp.) plantings in the United States. Previously known only from the southern United States $(15,18,23)$, hosta petiole rot had been reported in the northern United States with increasing frequency during the past decade (7).

In the northern United States, hosta petiole rot appears in mid- to late June or July after extended periods of warm, wet weather (15). S. rolfsii and $S$. rolfsii var. delphinii infect hosta at the base of the petiole, causing brown and macerated lesions. Leaves may turn yellow and wilt. White, fan-shaped mycelia and sclerotia can be seen on infected tissue and surrounding soil.

Corresponding author: M. L. Gleason

E-mail: mgleason@iastate.edu

Current address of C. A. Bradley: Department of Crop Sciences, University of Illinois, Urbana 61801.

Current address of P. D. Esker: Department of Plant Pathology, University of Wisconsin-Madison, Madison 53706.

Accepted for publication 13 December 2007.

doi:10.1094/PDIS-92-5-0719

(C) 2008 The American Phytopathological Society
$S$. rolfsii infects more than 600 species of vegetable, grain, and ornamental crops in more than 100 families (8). Over 270 host genera have been reported in the United States alone (8). S. rolfsii var. dephinii attacks at least 27 herbaceous ornamental species worldwide (8). Although these fungi are similar with regard to life cycle and disease management, $S$. rolfsii is distinct from $S$. rolfsii var. delphinii in morphology of sclerotia cultured in vitro, geographic distribution, and, probably, in host range (19). Anecdotal information suggests that $S$. rolfsii is more prevalent in relatively warm areas such as the southern United States, Brazil, and South Africa, whereas S. rolfsii var. delphinii has been reported primarily from cooler areas such as the northern and midwestern United States $(2,8,19)$. The cause of this apparent difference in geographic distribution is not known. It is possible that regional differences in temperature could affect the survival of $S$. rolfsii and $S$. rolfsii var. delphinii and thereby influence their geographic distribution, but no evidence supporting or refuting this hypothesis has been published.

Research on overwinter survival of these fungi has focused primarily on $S$. rolfsii and has shown that $S$. rolfsii survival was influenced by both location and environ- mental conditions $(1,2,25)$. Sclerotia survived in the soil from a few months to several years. Beute and RodriguezKabana (3) reported that 28 to $73 \%$ of sclerotia of $S$. rolfsii in soil survived up to 10 months in Alabama and North Carolina. In another study, sclerotia at the soil surface and buried in field soil survived at least 9 months in North Carolina and Georgia (22). In the United Kingdom, $S$. rolfsii var. delphinii was reported to survive in soil for 6 months to 2 years $(10,27)$. Some studies used sclerotia that were produced on agar media; such sclerotia are morphologically and physiologically distinct from sclerotia produced by natural infections $(12,18,20,22)$. Using sclerotia produced under controlled conditions that mimicked natural infections, Edmunds and Gleason (7) found that sclerotia of $S$. rolfsii var. delphinii survived 10 months in Iowa, until at least July of a subsequent growing season-long enough to have caused hosta petiole rot in the latter season. It is unclear, however, whether $S$. rolfsii var. delphinii can overwinter in the southern United States or $S$. rolfsii can overwinter in the northern United States.

Abiotic and biotic external factors can influence the survival of both fungi $(2,18)$. Larger size and, consequently, smaller surface:volume ratio, has been shown to increase survival of sclerotia of Sclerotium spp. (1). Although sclerotia of $S$. rolfsii var. delphinii are larger than those of $S$. rolfsii in agar plate culture, it is not known whether sclerotia of these fungi differ in size when produced under more natural conditions in the soil or on crop debris. If a size difference exists, it could be related to overwinter survival ability in a manner similar to that of other sclerotial fungi (1).

In this study, we tested the overwintering survival of $S$. rolfsii and $S$. rolfsii var. delphinii in different latitudes of the United States. This information is critical to test the hypothesis that overwinter survival differentially affects the geographic distribution of these fungi. Furthermore, knowledge on overwinter survival will shed new light on the ecology of both fungi and, thereby, could improve our ability to manage hosta petiole rot and other diseases incited by these fungi. The objective of this study was to compare the survival of sclerotia of $S$. rolfsii and $S$. 
rolfsii var. delphinii in the northern and southeastern United States.

\section{MATERIALS AND METHODS}

Isolates. Three isolates of $S$. rolfsii var. delphinii (Srd 1, obtained from an infected hosta [Hosta spp.] plant in Ankeny, IA; Srd 2 , obtained from an infected hosta plant in Ames, IA; and Srd 3, isolated from an infected iris [Iris spp.] in New Brunswick, Canada) and three isolates of $S$. rolfsii from Georgia (GA0006, designated here as $\mathrm{Sr}$ 1, isolated from an infected peanut [Arachis hypogaea] plant; GA03001 [Sr 2], isolated from an infected watermelon [Citrullus lanatus); and GA0009 [Sr 3], isolated from an infected peanut plant) were used in the study. Cultures were grown on potato dextrose agar (PDA; Difco Laboratories, Detroit) in 9-cmdiameter petri dishes under a daily regime of $8 \mathrm{~h}$ of incandescent light and $16 \mathrm{~h}$ of darkness at room temperature (20 to $23^{\circ} \mathrm{C}$ ).

Production of sclerotia. A single sclerotium of each isolate was placed on PDA in a 9-cm-diameter petri dish and incubated at $25^{\circ} \mathrm{C}$ under continuous incandescent light for 4 days. In order to mimic natural conditions for sclerotia production as closely as possible, 9-mm-diameter mycelial plugs from the edge of actively growing cultures on PDA were transferred onto cotton strips $(30 \mathrm{~cm}$ long, $2.5 \mathrm{~cm}$ wide, and $1 \mathrm{~cm}$ thick) that had been placed on a 3-cm-deep layer of sterilized moist sand in plastic crispers (7). Lids then were placed loosely on the crispers, and the crispers were incubated in dew chambers (Percival Inc., Perry, IA) at $27^{\circ} \mathrm{C}$ and $100 \%$ relative humidity with a 12 -h-light and 12-h-darkness regime. After 2 weeks, sclerotia that had formed on the cotton strips were brushed into a glass petri dish and stored in a sealed plastic crisper at room temperature.

Germination of sclerotia was tested initially on 20 October 2005 . For each isolate of S. rolfsii var. delphinii (Srd 1 and Srd 2) and $S$. rolfsii ( $\mathrm{Sr} 1$ and $\mathrm{Sr}$ 2), 100 sclerotia were assessed. Viability of sclerotia was evaluated on Bacto agar amended with carrot puree, tetracycline hydrochloride (150 mg/liter), and streptomycin sulfate (150 mg/liter) (carrot agar) (7). Carrot puree was prepared 3 weeks in advance by blending twice-autoclaved carrots at high speed for $30 \mathrm{~s}$, dividing the puree into 200$\mathrm{ml}$ plastic beakers, and freezing them. Carrot agar was prepared 1 day before plating.

Field experiment. Bags to contain sclerotia were made from $0.5-\mathrm{mm}$-mesh nylon screen by sewing together two 15-by-15$\mathrm{cm}$ squares with polyester thread along three sides. Twenty-five sclerotia of an isolate were placed in each bag and the open end of the bag then was sewed shut. The nylon bags containing sclerotia subsequently were stored in plastic bags in a crisper at $25^{\circ} \mathrm{C}$ for 1 week before deployment in the field.

In 2005, 192 bags were placed at each site (two fungi $\times$ two isolates per fungus [Srd1, Srd2, Sr1, and Sr2] $\times$ two soil depths [surface and $20 \mathrm{~cm}$ ] $\times$ six sampling times $\times$ four replications per sampling time). Paired bags (surface and $20-\mathrm{cm}$ depth) were deployed approximately $1 \mathrm{~m}$ apart in a randomized complete block design with four replications (block). Bags were placed on the soil surface or buried at 20-cm depth individually. Location and deployment dates were as follows: 24 October at the North Dakota State University Agricultural Experiment Station, Fargo (N $46.900^{\circ}, \mathrm{W} 96.819^{\circ}$; the site had dry edible bean [Phaseolus vulgaris] in 2005 and soybean [Glycine max] in 2004); 26 October at the Iowa State University Horticulture Station, Gilbert (N 42.109 ${ }^{\circ}$, W 93.589 $9^{\circ}$; the site had no crops planted before); 3 November at North Carolina State University, Central Crops Research Station, Clayton (N 35.670 ${ }^{\circ}$ W $78.493^{\circ}$; the site had tobacco [Nicotiana spp.] 2 years before the experiment was started and was fallow the year before the experiment was started); and 12 November at the Dempsey Research Farm, Griffin-

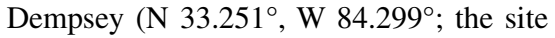
had been planted with daylily [Hemerocallis spp.] for 2 years prior to the experiment). Bags on the soil surface were secured by landscape staples. The soil types at each location were Silty clay (fine, smectitic, frigid Typic Epiaquerts) with 40 to $60 \%$ clay, 40 to $60 \%$ silt, and $<15 \%$ sand; Storden loam (fine-loamy, mixed, superactive, mesic Typic Eutrudepts) with 18 to $27 \%$ clay, 63 to $82 \%$ silt, and 35 to $40 \%$ sand; Fuquay sand (loamy, siliceous, thermic, arenic plinthic Kandiudult) with 5 to $18 \%$ clay, 80 to $100 \%$ silt, and 55 to $85 \%$ sand; and Cecil sandy clay loam (clay, kaolinitic, thermic Typic Hapludult) with 25 to $35 \%$ clay, 63 to $80 \%$ silt, and 45 to $100 \%$ sand, respectively.

Assessment of survival. At each sampling time, four bags were retrieved from each depth at each location, placed in insulated chests, and delivered to Iowa State University (ISU). At ISU, bags were rinsed under running tap water until they were free of adhering soil. In a laminar-flow hood, bags with sclerotia were surface sterilized in $10 \% \mathrm{NaOCl}$ for $90 \mathrm{~s}$ and in 95\% alcohol for $30 \mathrm{~s}$, rinsed for 1 min with sterilized deonized water, rinsed again for $1 \mathrm{~min}$ with sterilized deonized water, and then blotted dry between paper towels. After bags were cut open, sclerotia were removed with sterilized forceps and placed in an empty sterile petri dish.

Sclerotia were transferred from the petri dish five at a time, placed equidistant from each other on the surface of a carrot agar plate, and incubated under continuous light at $25^{\circ} \mathrm{C}$. A sclerotium was scored as viable if it produced a characteristic white fan- like mycelium in culture after $48 \mathrm{~h}$ of incubation. Sclerotia that did not germinate after $48 \mathrm{~h}$ were transferred to a new carrot agar plate, incubated for an additional 48 $\mathrm{h}$, and then re-rated for viability as described above.

Evaluation of sclerotia size. In all, 100 sclerotia of each of three isolates of $S$. rolfsii var. delphinii (Srd 1, Srd 2, and Srd 3 ) and 3 isolates of $S$. rolfsii from Georgia ( $\mathrm{Sr} 1, \mathrm{Sr} 2$, and $\mathrm{Sr} 3$ ) were produced as described above and collected in petri dishes. Sclerotia and an adjacent ruler were photographed under a dissecting microscope. In Photoshop 7.0 (Adobe Inc, $\mathrm{CA}$ ), diameter of sclerotia in the digital images was measured as pixel size, which was calibrated against pixel size of the ruler image.

Weather data. Average daily air temperature (1 to $2 \mathrm{~m}$ above the ground) and soil temperature (20-cm depth), based on hourly measurements at automated weather stations, were downloaded from the North Dakota Agricultural Weather Network (Fargo), the Iowa Agriculture Climate Network (ISU Agronomy Farm Station, Ames), the State Climate Office of North Carolina (Central Crops Research Station, Clayton), and the Georgia Automated Environmental Monitoring Network (Griffin) during the entire exposure period for sclerotia. All weather stations were located within $30 \mathrm{~km}$ of the field experiment sites.

Data analysis. The percentage of viable sclerotia remaining in the bags at the soil surface and at 20-cm depth was calculated for each location and sampling time. Sclerotium survival was determined by counting the number of viable sclerotia and dividing by 25 , the original number of sclerotia buried. Data were analyzed using the SAS PROC Mixed procedure (SAS Institute, Cary, NC). Data for percentage of viable sclerotia were subjected to arcsin transformation in order to meet analysis of variance assumptions of normality. Isolates of each fungus were treated as a random factor. Treatment means were compared using the Tukey studentized range multiple comparison adjustment $(P<0.05)$. The apparent daily death rate of sclerotia was calculated as follows: $r=(-1 / \Delta t) \ln \left(N_{t} / N_{t-1}\right)$, in which $\Delta t=$ time increment (days) between two sampling dates; $N_{t}=$ percentage of viable sclerotia at sampling date $t$; and $N_{t-1}=$ percentage of viable sclerotia at sampling date $t-1$ (24). Data for evaluation of sclerotia size were analyzed using the SAS PROC GLM procedure (SAS Institute).

\section{RESULTS}

Some sclerotia of $S$. rolfsii var. delphinii survived until at least July in all four states (Fig. 1). In contrast, no $S$. rolfsii sclerotia survived until June in either North Dakota or Iowa, whereas $18.5 \%$ survived until August in North Carolina and $10.3 \%$ in 
Georgia. S. rolfsii var. delphinii had a significantly $(P<0.05)$ higher percentage of survival than $S$. rolfsii in the northern states on most sampling dates, whereas no clear differences between the fungi were observed in the southeastern states.

From May through July, there was no statistical difference in percentage of viable sclerotia of either fungus at the soil surface compared with the $20-\mathrm{cm}$ depth at any location (Fig. 1). In general, sclerotia survival for both species was slightly greater at the $20-\mathrm{cm}$ soil depth than at the soil surface.

In North Dakota and Iowa, apparent daily death rate (r) of $S$. rolfsii sclerotia increased sharply in the spring, whereas the increase for $S$. rolfsii var. delphinii was less pronounced (Fig. 2A-D). For S. rolfsii, the maximum values of $\mathrm{r}$ were 0.178 (soil surface) and 0.197 (20-cm depth) in North Dakota, and 0.12 (soil surface) and 0.243 (20-cm depth) in Iowa; whereas, for $S$. rolfsii var. delphinii, the maximum values of $r$ were 0.043 (soil surface) and 0.04 (20-cm depth) in North Dakota, and 0.021 (soil surface) and 0.05 (20-cm depth) in Iowa. In North Carolina and Georgia, apparent daily death rate showed no sharp increase from April to June for either fungus, and there was little difference in rates between the fungi (Fig. 2E-H).

In North Dakota, average daily air temperature dropped as low as -17 and $-19^{\circ} \mathrm{C}$ in December and March, respectively (Fig. 3A). Similarly, air temperature in Iowa fell as low as $-19^{\circ} \mathrm{C}$ in early December and $-20^{\circ} \mathrm{C}$ in late February (Fig. 3C). In contrast, minimum average daily air temperature in North Carolina was $-2^{\circ} \mathrm{C}$ in the middle of December and always exceeded $0^{\circ} \mathrm{C}$ in Georgia (Fig. 3E and G). In North Dakota and Iowa, average daily soil temperature $\left(20-\mathrm{cm}\right.$ depth) was $0^{\circ} \mathrm{C}$ or below throughout the winter and early spring, but seldom fell below $5^{\circ} \mathrm{C}$ in North Carolina or Georgia (Fig. 3B, D, F, and H).

Average diameter of sclerotia of three isolates of $S$. rolfsii var. delphinii (1.52 $\mathrm{mm}$ ) was $63 \%$ larger than that of $S$. rolfsii (0.93 mm). (Table 1).

\section{DISCUSSION}

The findings are the first evidence that S. rolfsii may be unable to overwinter long enough in the northern United States to persist as a pathogen of hosta or other crops from year to year. In contrast, survival of $S$. rolfsii var. delphinii in the northern United States until at least June (long enough for infection and petiole rot to occur) was consistent with findings of Edmunds and Gleason (7).

A possible explanation for the apparent predominance of $S$. rolfsii var. delphinii as the hosta petiole rot pathogen in the north may be the inability of $S$. rolfsii sclerotia to survive in this region until June, when the onset of warmer temperatures increases the risk of petiole rot.

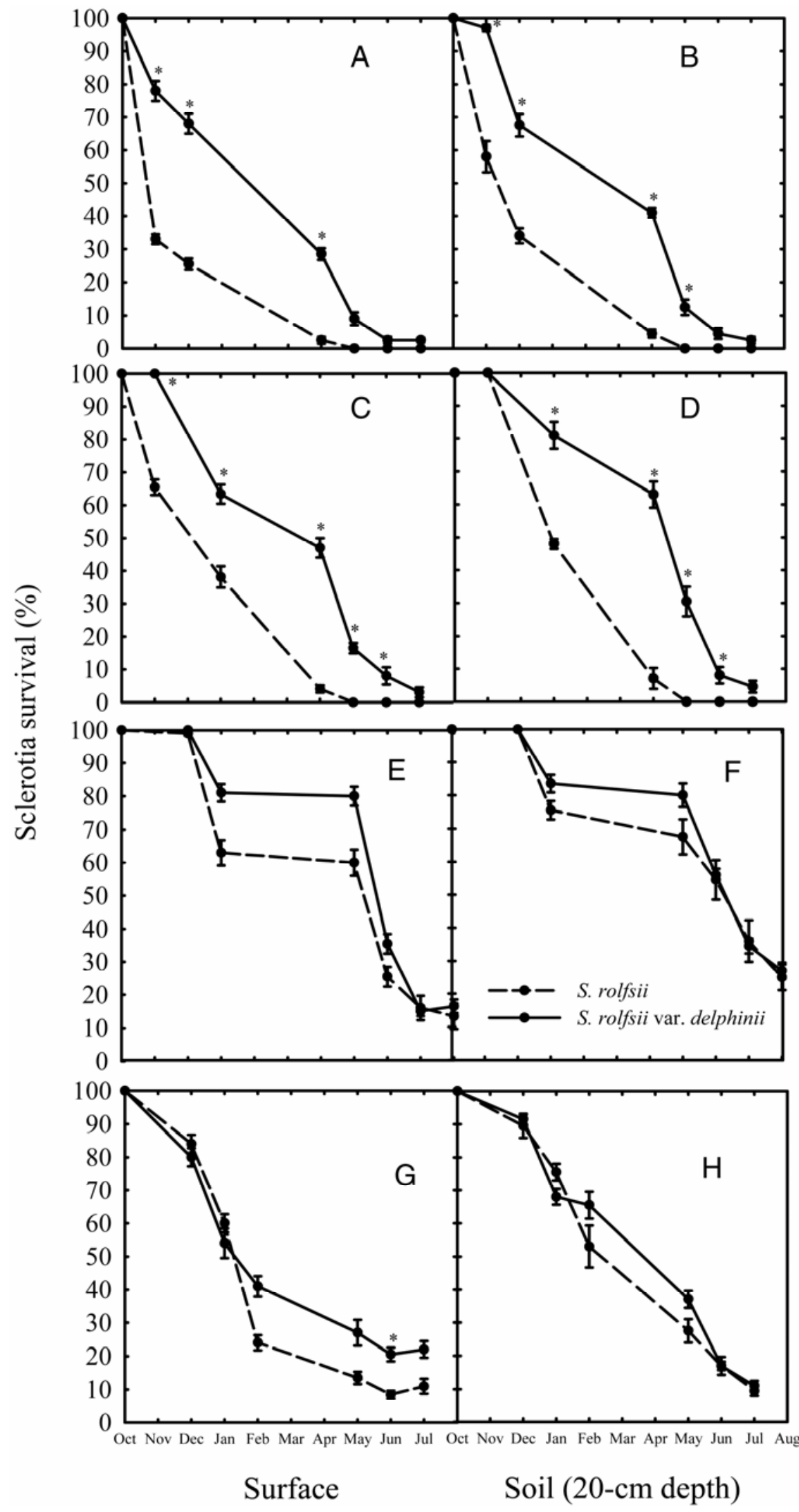

Fig. 1. Mean percent survival of sclerotia of Sclerotium rolfsii isolates ( $\mathrm{Sr} 1$ and $\mathrm{Sr} 2$ ) and S. rolfsii var. delphinii isolates (Srd 1 and Srd 2) at the soil surface and at 20-cm soil depth, respectively, in $\mathbf{A}$ and $\mathbf{B}$, Fargo, ND; C and D, Gilbert, IA; E and F, Clayton, NC; and $\mathbf{G}$ and H, Griffin, GA from October 2005 to August 2006. Significant differences $(P<0.05)$ in survival between $S$. rolfsii and $S$. rolfsii var. delphinii on sampling dates (marked with asterisks): November, December, April, and May for both soil surface and 20-cm in the soil in North Dakota; November, January, April, May, and June for soil surface and January, April, May, June, and July for $20-\mathrm{cm}$ in the soil in Iowa; and June for soil surface in Georgia according to the Tukey test. 
In North Dakota and Iowa, lower average daily air and soil temperature in winter corresponded with lower survival of $S$. rolfsii during late winter than in North Carolina and Georgia.. The apparent absence of $S$. rolfsii in areas with severe winters may be due to its inability to tolerate low temperatures (2). In contrast, sclerotia of $S$. rolfsii var. delphinii appeared to tolerate severe winter temperatures based on our results.

We also found that both $S$. rolfsii and $S$. rolfsii var. delphinii can survive until at least August in the southeastern states.

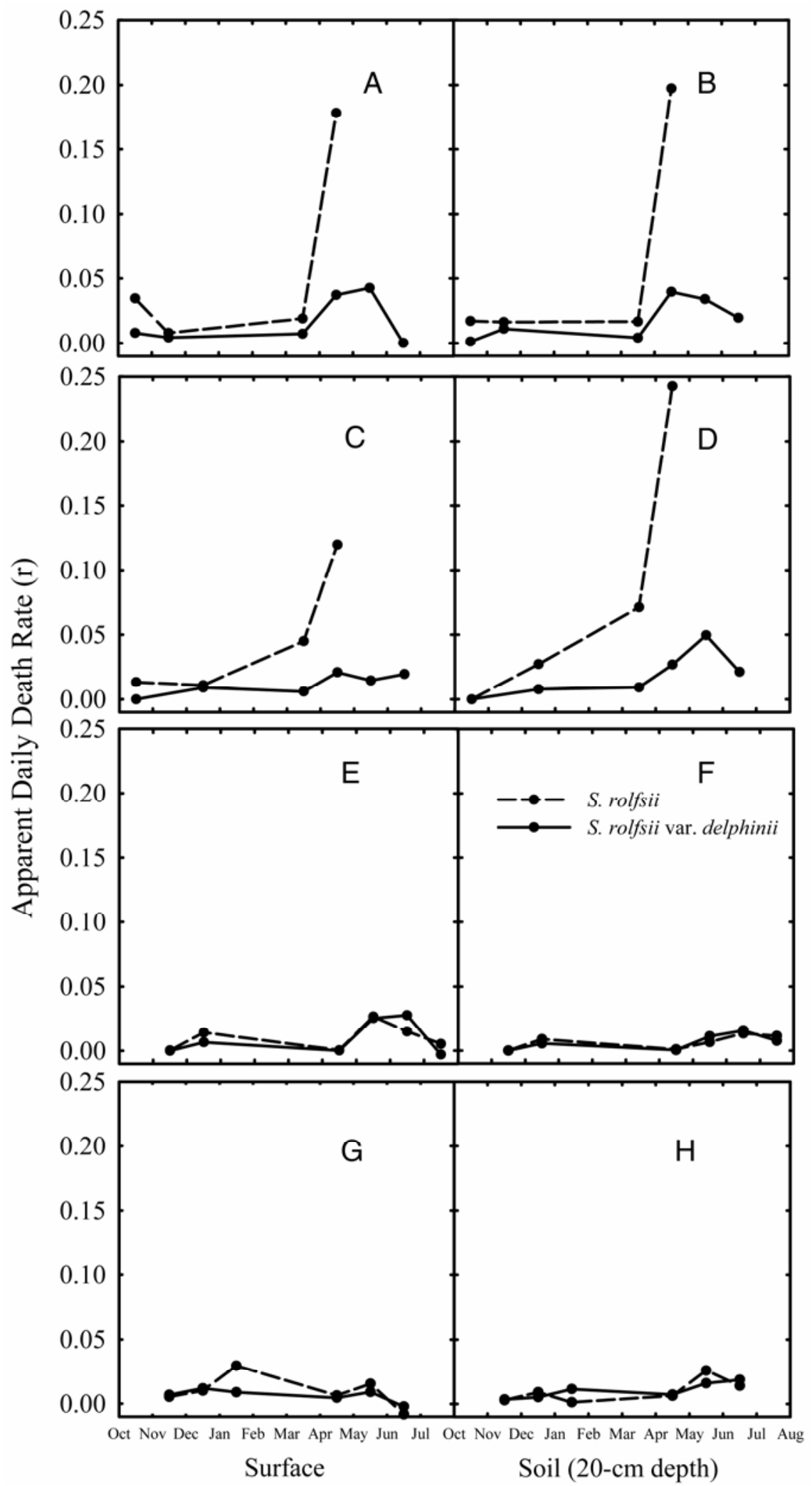

Fig. 2. Apparent daily death rate at the surface and at 20-cm depth in the soil, respectively for $\mathbf{A}$ and $\mathbf{B}$, North Dakota; $\mathbf{C}$ and D, Iowa; $\mathbf{E}$ and $\mathbf{F}$, North Carolina; and $\mathbf{G}$ and $\mathbf{H}$, Georgia.

This is the first quantified report of overwinter survival of $S$. rolfsii var. delphinii in the southern United States. The apparent absence of $S$. rolfsii var. delphinii in the southeastern states, however, is not explained by our results. It is possible that other factors may limit distribution and dispersal of $S$. rolfsii var. delphinii in this region. In addition to differential overwinter survival, the two fungi differ in optimum growth temperature. Punja and Daminai (19) found that $S$. rolfsii had a higher optimum temperature for sclerotial production than $S$. rolfsii var. delphinii, which may favor prevalence of $S$. rolfsii in warmer regions. It is also possible that $S$. rolfsii var. delphinii occurs in the South but has been misidentified as $S$. rolfsii. The fact that disease symptoms and signs of the two pathogens (mycelia and sclerotia) in vivo may be indistinguishable to the naked eye make this a plausible possibility.

Colonization of sclerotia by Fusarium oxysporum, F. tricinctum, Alternaria spp., Aspergillus spp., Cladosporium spp., Penicillium spp., and other fungi, as well as empty rinds of sclerotia, were common in May or June at all locations ( $\mathrm{Z}$. Xu, unpublished data).

For both fungi, the coincidence of increasing apparent daily death rate of sclerotia in the spring or early summer with rising temperatures suggests that mortality was associated with an upsurge in colonization by soil microbiota (18).

Overwinter survival of $S$. rolfsii sclerotia in North Carolina and Georgia was consistent with results of previous studies in these states $(3,22)$. In contrast to our findings, however, a growth chamber study (3) and a field study (22) indicated that survival of sclerotia was greater at the soil surface than when buried at a 5- to $15-\mathrm{cm}$ depth. In Iowa, Edmunds and Gleason (7) found that survival of $S$. rolfsii var. delphinii was not significantly affected by depth of burial until June and July and that the magnitude of this difference varied among locations. In general, we found that sclerotial survival at the surface was slightly lower but not statistically different than at $20-\mathrm{cm}$ depth throughout the experiment. Variability in the results suggests that the effectiveness of burial in preventing overwinter survival of sclerotia may depend on site- or regionspecific factors (1).

Alexander and Stewart (1) found that sclerotia of $S$. rolfsii survived longer than those of Sclerotinia minor and Sclerotium cepivorum and attributed the greater survival to larger sclerotia, which may contain more nutrients in the cortex and be more resistant to unfavorable conditions $(1,4)$. In the two cold-winter sites in the present study, S. rolfsii var. delphinii survived better than $S$. rolfsii, which may indicate that $S$. rolfsii var. delphinii sclerotia are more resistant to very low temperatures. A larger sclerotium possesses a smaller surface:volume ratio, which means that the 
cortex is less exposed to the environment (21). Larger size thus confers a protective effect by shielding the cortex from temperature extremes and microbial attack.
Further experimentation is needed to confirm or refute this hypothesis. In Georgia and North Carolina, however, survival of $S$. rolfsii var. delphinii generally exceeded

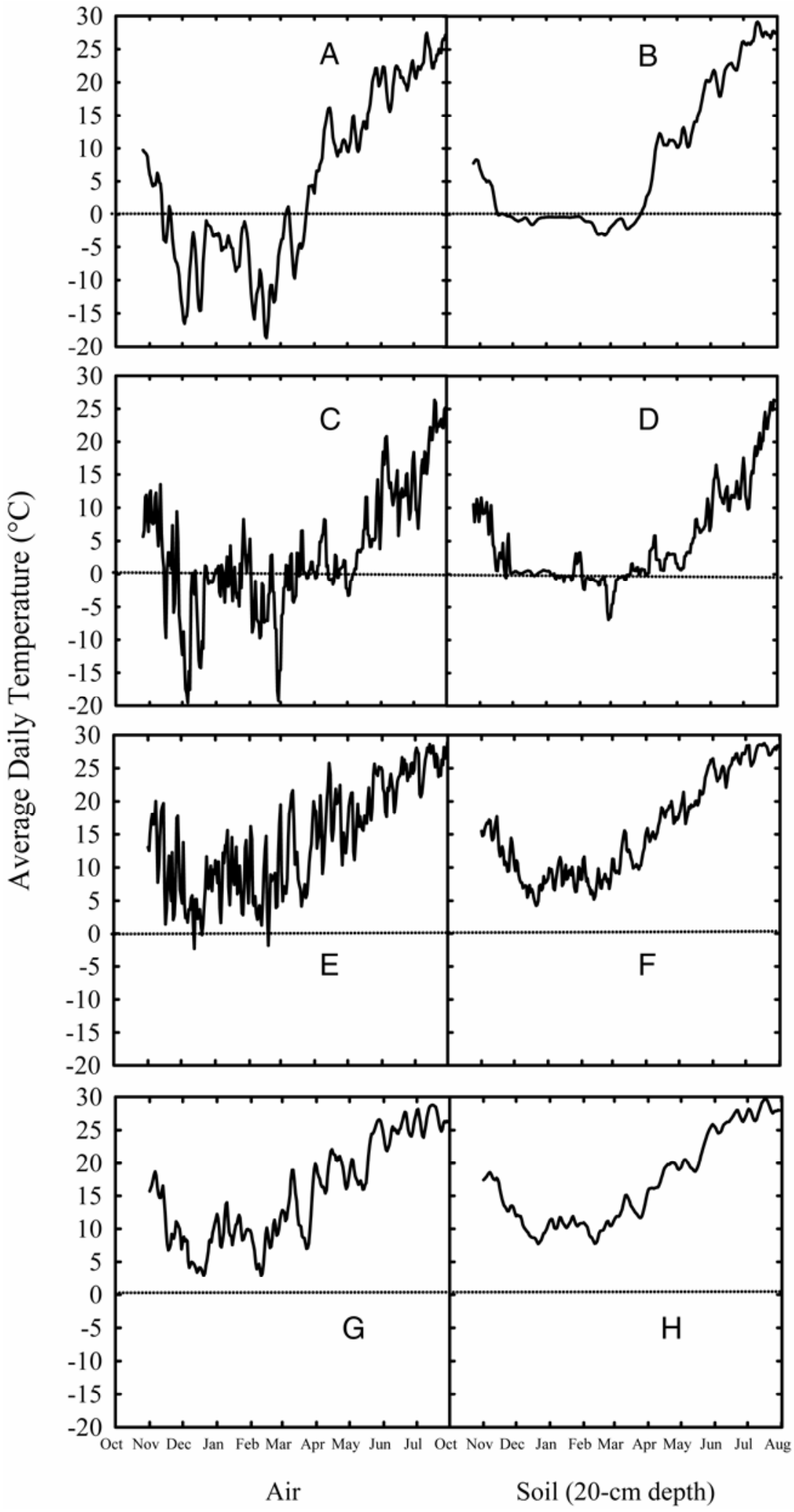

Fig. 3. Average daily air temperature and 20-cm soil temperature, respectively, for $\mathbf{A}$ and $\mathbf{B}$, North Dakota; $\mathbf{C}$ and D, Iowa; $\mathbf{E}$ and $\mathbf{F}$, North Carolina; and $\mathbf{G}$ and $\mathbf{H}$, Georgia. Dates having snow cover on the ground were 15 to 17 and 25 November 2005 to 29 March 2006 for Moorhead, MN (total numbers of snow cover days $=128$ ) and 15 to 17 and 29 to 30 November and 1 to 31 December 2005, 1 to 2 and 20 to 22 January, 8 to 12 and 16 to 19 February, and 21 to 24 March 2006 for Iowa State University Agronomy Farm (total numbers of snow cover days $=54$ ). Both weather stations were within $30 \mathrm{~km}$ of the experiment. that of $S$. rolfsii, suggesting that $S$. rolfsii var. delphinii sclerotia may have superior resistance to other, unidentified environmental factors in addition to temperature.

Soil texture also may affect survival of sclerotia (13). Mitchell and Wheeler (14) and Alexander and Stewart (1) showed more rapid sclerotial degradation and lower sclerotia survival in higher clay content soil. Alexander and Stewart (1) argued that this could have resulted from higher water retention and higher levels of microbial activity in clay soil. The fact that survival of both fungi were generally greater in Iowa (Storden loam) than in North Dakota (Silty clay) and survival in North Carolina (Fuquay sand) exceeded that in Georgia (Cecil clay sandy loam) may be related to different clay content in each location. The extent to which soil characteristics at the four sites may have influenced sclerotial survival is unknown. However, greater similarity of survival trends within regions than within soil type suggests that temperature-related influences were stronger.

In previous studies, sclerotia of $S$. rolfsii were found to survive from 2 months to 3 years in field soil (2) and $S$. rolfsii var. delphinii survived 6 months to 2 years $(5,10,11,26,27)$. Some of those studies used sclerotia that were either produced on culture media or air dried before burial; it is likely, however, that conditions under which sclerotia are produced can impact their durability in survival trials. Sclerotia produced from natural infections differ physiologically and structurally from those produced on culture media $(3,12,18$, 20,22). Linderman and Gilbert (12) suggested that naturally produced sclerotia are more uniform in size and should be used in experiments. Sclerotia produced on rich media also have a thicker cortex than those produced under natural conditions. Sclerotia formed under natural conditions are likely to be more adversely affected by environment in the soil and to have a lower rate of survival than those formed on agar plates $(1,6)$. Our method of producing sclerotia represented a compromise between in vivo and in vitro conditions that facilitated rapid, consistent production of large numbers of similar sclerotia under

Table 1. Comparison of diameter of sclerotia of Sclerotium. rolfsii and $S$. rolfsii var. delphinii

\begin{tabular}{lcc}
\hline Fungi, isolate & $\begin{array}{c}\text { Diameter } \\
(\mathbf{m m})\end{array}$ & $\begin{array}{c}\text { Standard } \\
\text { deviation }\end{array}$ \\
\hline S. rolfsii & & \\
Sr 1 & 0.93 & 0.108 \\
Sr 2 & 0.94 & 0.110 \\
Sr 3 & 0.92 & 0.117 \\
Mean & 0.93 & 0.125 \\
S. rolfsii var. delphinii & & \\
Srd 1 & 1.48 & 0.289 \\
Srd 2 & 1.48 & 0.384 \\
Srd 3 & 1.59 & 0.414 \\
Mean & 1.52 & 0.532 \\
\hline
\end{tabular}


simulated natural conditions. Morphology of sclerotia produced by our technique closely resembled that of sclerotia produced in field infections of hosta petiole $\operatorname{rot}(\mathrm{Z} . \mathrm{Xu}$, unpublished data).

The results of this study supported the hypothesis that overwinter survival can impact the biogeography of $S$. rolfsii and $S$. rolfsii var. delphinii. Additional studies measuring multiple environmental factors will be required to achieve a clearer understanding of overwintering survival in these fungi. Improved diagnostic procedures, combining polymerase chain reaction assays $(9,16,17)$ and examination of sclerotial size and morphology in culture, would be helpful in identifying these pathogens rather than assuming identity based solely on field signs.

\section{ACKNOWLEDGMENTS}

We thank C. D. Chesrown, K. Parker, J. D. Youmans, M. Priebe, A. Sisson, and J. Massman for assistance with sample collection; Z. K. Punja for providing isolates of $S$. rolfsii; J. C. Batzer, M. Agudelo, E. Schaefer, and D. Wynthein for assistance with producing sclerotia and making nylon bags; and D. Volkers for maintaining the dew chamber.

\section{LITERATURE CITED}

1. Alexander, B. J. R., and Stewart, A. 1994. Survival of sclerotia of Sclerotinia and Sclerotium spp. in New Zealand horticultural soil. Soil Biol. Biochem. 26:1323-1329.

2. Aycock, R. 1966. Stem rot and other diseases caused by Sclerotium rolfsii. N. C. Agric. Exp. Stn. Tech. Bull. No. 170.

3. Beute, K., and Rodriguez-Kabana, R. 1981. Effects of soil moisture, temperature, and field environment on survival of Sclerotium rolfsii in Alabama and North Carolina. Phytopathology 71:1293-1296.
4. Chet, I. 1975. Ultrastructural basis of sclerotial survival in soil. Microbiol. Ecol. 2:194-200.

5. Coley-Smith, J. R., Ghaffar, A., and Javed, Z. U. R. 1974. The effect of dry conditions on subsequent leakage and rotting of fungal sclerotia. Soil Biol. Biochem. 6:307-312.

6. Coley-Smith, J. R., Mitchell, C. M., and Sansford, C. E. 1990. Long-term survival of sclerotia of Sclerotium cepivorum and Stromatinia gladioli. Plant Pathol. 39:58-69.

7. Edmunds, B. A., and Gleason, M. L. 2003. Perennation of Sclerotium rolfsii var. delphinii in Iowa. Online. Plant Health Progress doi:10.1094/PHP-2003-1201-01-RS.

8. Farr, D. F., Rossman, A.Y., Palm, M. E., and McCray, E. B. (n.d.) 2006. Fungal Databases. Systematic Botany \& Mycology Laboratory, ARS, USDA. http://nt.ars-grin.gov/fungaldata bases/.

9. Harlton, C. E., Levesque, C. A., and Punja, Z. K. 1995. Genetic diversity in Sclerotium (Athelia) rolfsii and related species. Phytopathology 85:1269-1281.

10. Javed, Z. U. R., and Coley-Smith, J. R. 1973. Studies on germination of sclerotia of Sclerotium delphinii. Trans. Br. Mycol. Soc. 60:441-451.

11. Javed, Z. U. R., and Coley-Smith, J. R. 1977. Studies of the behaviour in soil of five sclerotium-forming fungi. Trans. Mycol. Soc. Jpn. 18:111-118.

12. Linderman, R. G., and Gilbert, R. G. 1973. Behavior of sclerotia of Sclerotium rolfsii produced in soil or in culture regarding germination stimulation by volatiles, fungistatis, and sodium hypochlorite treatment. Phytopathology 63:500-503.

13. Merriman, P. R. 1976. Survival of sclerotia of Sclerotinia sclerotiorum in soil. Soil Biol. Biochem. 8:385-389.

14. Mitchell, S. J., and Wheeler, B. E. J. 1990. Factors affecting the production of apothecia and longevity of sclerotia of Sclerotinia sclerotiorum. Plant Pathol. 39:70-76.

15. Mullen, J. 2001. Southern blight, Southern stem blight, White mold. The Plant Health In- structor. doi:10.1094/PHI-I-2001-0104-01.

16. Okabe, I., and Matsumoto, N. 2003. Phylogenetic relationship of Sclerotium rolfsii (teleomorph Athelia rolfsii) and S. delphinii based on ITS sequences. Mycol. Res. 107:164-168.

17. Okabe, I., Morikawa, C., Matsumoto, N., and Yokoyama, K. 1998. Variation in Sclerotium rolfsii isolates in Japan. Mycoscience 39:399407.

18. Punja, Z. K. 1985. The biology, ecology, and control of Sclerotium rolfsii. Ann. Phytopathol. 23:97-127.

19. Punja, Z. K., and Damiani, A. 1996. Comparative growth, morphology, and physiology of three Sclerotium species. Mycologia 88:694706.

20. Punja, Z. K., Jenkins, S. F., and Grogan, R. G. 1984. Effect of volatile compounds, nutrients, and source of sclerotia on eruptive germination of Sclerotium rolfsii. Phytopathology 74:12901295.

21. Schmidt-Nielson, K. 1984. Scaling: Why is Animal Size so Important? Cambridge University Press, New York.

22. Smith, V. L., Jenkins, S. F, Punja, Z. K., and Benson, D. M. 1989. Survival of sclerotia of Sclerotium rolfsii: Influence of sclerotial treatment and depth of burial. Soil Biol. Biochem. 21:627-632.

23. Tian, D. 2006. Southern blight: deadly curse for peonies. Am. Nurseryman Vol. 204, No. 8.

24. Vanderplank, J. E. 1963. Plant Diseases: Epidemics and Control. Academic, New York.

25. Willetts, H. J. 1971 The survival of fungal sclerotia under adverse environmental conditions. Biol. Rev. 46:387-407.

26. Williams, G. H., and Western, J. H. 1965. The biology of Sclerotium trifoliorum Erikss. and other species of sclerotium-forming fungi: I. Apothecium formation from sclerotia. Ann. Appl. Biol. 56:253-260.

27. Williams, G. H., and Western, J. H. 1965. The biology of Sclerotium trifoliorum Erikss. and other species of sclerotium-forming fungi: II The survival of sclerotia in soil. Ann. Appl. Biol. 56:261-268. 